\title{
Oral bisphosphonates for the risk and survival of colorectal cancer: a quantitative synthesis of observational studies
}

\author{
Kai Xu' ${ }^{1, *}$, Gang Peng ${ }^{2, *}$ and Yingchao Zhao ${ }^{2}$ \\ ${ }^{1}$ Department of Otolaryngology-Head and Neck Surgery, Tongji Hospital, Tongji Medical College, Huazhong University of \\ Science and Technology, Wuhan 430022, China \\ ${ }^{2}$ Cancer Center, Union Hospital, Tongji Medical College, Huazhong University of Science and Technology, Wuhan 430022, \\ China \\ "These authors contributed equally to this work
}

Correspondence to: Yingchao Zhao, email: yingchaozhao321@126.com

Keywords: bisphosphonate; colorectal cancer; risk; survival; observational study

Received: August 23, $2017 \quad$ Accepted: October 13, $2017 \quad$ Published: December 16, 2017

Copyright: $\mathrm{Xu}$ et al. This is an open-access article distributed under the terms of the Creative Commons Attribution License 3.0 (CC BY 3.0), which permits unrestricted use, distribution, and reproduction in any medium, provided the original author and source are credited.

\section{ABSTRACT}

Several preclinical studies have suggested that bisphosphonates (BPs) may have anti-neoplastic effects against colorectal cancer (CRC). However, the magnitude of this association has not been fully determined. The aim of this study was to synthesize the existing evidence on the association between BP intake and risk or mortality of CRC. Three relevant databases including Pubmed, Embase and Cochrane Library were searched from initial to August 2017. Combined relative risks (RRs)or hazard ratios (HRs) with $95 \%$ confidence interval $(95 \% \mathrm{CI})$ were pooled using a random-effects model. Thirteen studies enrolling 3,464,335 individuals were eligible for inclusion, with 11 studies investigating associations between BP use and CRC risk and 3 studies examining BP use and CRC mortality. Comparing with non-BP users, the summary RRs for CRC risk in BP users were 0.87 (95\% CI, 0.79 to 0.97$)$. Subgroup analyses revealed that this association was robust for nested case-control studies and especially evident for rectal cancer. We did not find survival benefits of BP use for CRC patients in terms of overall survival (HR $0.74,95 \%$ CI 0.43 to 1.27 ) or cancer-specific survival (HR $0.71,95 \%$ CI 0.44 to 1.15 ). Our findings suggest that oral BP use may be associated with reduced risk of CRC, while further larger cohort studies should be advocated to determine the true relationship between BP use and CRC mortality in specific patients.

\section{INTRODUCTION}

As a commonly used drug for the treatment and prevention of osteoporosis [1, 2], bisphosphonates (BPs) have been widely prescribed to increase bone density for patients with osteopenia or osteoporosis [3]. Numorous preclinical studies have shown that BPs have antineoplastic effects and reduce bone metastases in cancer patients, which have been mostly reported in breast cancer [4]. BPs act as anti-cancer agents in that they are reported to play anti-proliferative and proapoptotic role, inhibit cancer cell adhesion, invasion, angiogenesis and immunomodulation [5-8].

Several large population-based observational studies have reported that BP use is associated with reduced risk of CRC. The Molecular Epidemiology of Colorectal Cancer (MECC) study reported a reduced risk by $59 \%$ of CRC for Postmenopausal women with BP use for one year [9]. Similar findings were also observed in two nested case-control studies from the United Kingdom General Practice Research Database (GPRD)[10, 11] and the Manitoba Drug Program Information Network [12]. However, another report from Danish National Prescription Database found no association between BP use and CRC risk [13]. Moreover, only a few studies reported associations between $\mathrm{BP}$ use and CRC mortality with conflicting results [14-16]. Hence, the purporse of this study was to conduct a systematic review and metaanalysis to synthesize the evidence about the association between BP intake and risk or survival in CRC patient. 


\section{RESULTS}

\section{Search and selection of studies}

The computer-assisted literature search yielded a total of 1491 citations. After the removal of duplications, 1307 titles/abstracts appeared to be potentially appropriate and were selected for full text review (Figure 1). Totally, 13 studies met all inclusion criteria for meta-analysis [9-12, 14-22].

\section{Study characteristics}

Thirteen studies enrolling 3,464,335 individuals were eligible for inclusion, with 11 studies investigating associations between BP use and CRC risk [9-12, 16-22] and 3 studies examining BP use and CRC mortality [1416]. Four were initiated in USA or Canada, six in Europe and three in Asia. Six studies recruited female participants and two enrolled male participants. The median number of sample size of the included studies was 127586 (range, 1866 to 1000000$)$. Seven of the included studies were cohort studies and six were nested case-control studies. The most frequently type of BP used were alendronate, etidronate, ibandronate, risedronate and tiludronate. The exposure ascertainment of most of the studies was from pharmacy record of filling of prescription. The mean/ median follow-up years ranged from 3.3 to 12 years. All of the studies used multivariate analysis to generate outcome estimates (Supplementary Table 1).

\section{$\mathrm{BP}$ intake and risk of $\mathrm{CRC}$}

Meta-analysis based on 11 cohort or nested casecontrol studies assessing BP use and CRC risk indicated that compared with non-use, BP use was significantly associated with decreased risk of CRC (RR 0.87, 95\% CI 0.79 to 0.97 , Figure $2 \mathrm{~A}$ ), with significant heterogeneity among studies $\left(\mathrm{I}^{2}=85.1 \%\right)$. Subgroup analysis when involving only male or female participants showed similar results (male: RR $0.84,95 \%$ CI 0.76 to 0.92 ; female: RR 0.85 , 95\% CI 0.75 to 0.96). Subgroup analysis also revealed that this association was robust for nested case-control studies (RR $0.84,95 \%$ CI 0.73 to 0.97 ), especially evident for rectal cancer (RR $0.70,95 \%$ CI 0.55 to 0.90 ).

We did not find any evidence of publication bias by visual inspection of the funnel plot (Figure 3), which was further confirmed with Egger's test $(P=0.720)$ or Begg's test $(P=0.755)$. We further adjusted the pooled

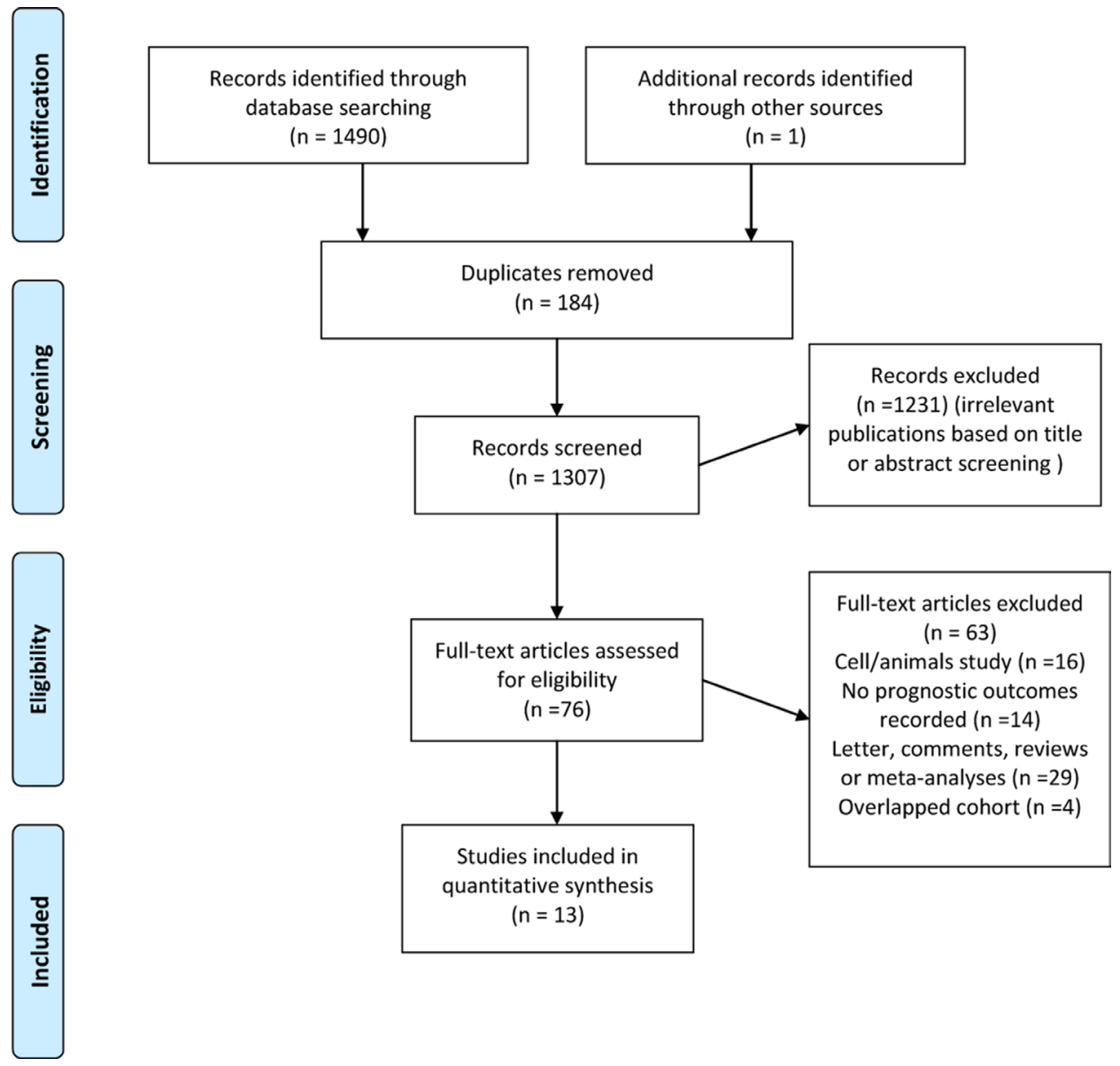

Figure 1: Flow diagram of study selection. 
risk estimate using the trim-and-fill method and the result remained constant with the original analysis.

\section{BP intake and survival of CRC}

Meta-analysis based on 3 cohort studies assessing $\mathrm{BP}$ use and CRC survival indicated that no survival benefits were observed for associations between $\mathrm{BP}$ use and CRC prognosis in terms of overall survial (HR 0.74, $95 \%$ CI 0.43 to 1.27 ) or cancer-specific survival (HR 0.71 , $95 \%$ CI 0.44 to 1.15 ) Figure 2B. We did not further test the publication bias for OS or CSS due to the limited number of studies involved.

\section{DISCUSSION}

Given the evidence to date that BP intake in participants is associated with reduced risk of CRC, it is of great significance to determine the risk in individuals who are prescribed BPs. This meta-analysis suggest that the risk of developing CRC with BP use is slightly elevated and loses significance when cohort studies are excluded. In terms of CRC prognosis, we did not find survival benefits of BP use for CRC patients in terms of overall survival and cancer-specific survival.

For the analysis of association between BP use and $\mathrm{CRC}$ risk, we observed a significant inter-study heterogeneity $\left(\mathrm{I}^{2}=85.1 \%\right)$. In sensitivity analysis by trim and filled method, the result of the adjusted pooled estimate did not alter. We also noted that the heterogeneity moderately or significantly diminished for some of the investigated variables such as gender, tumor site and research region (Table 1), which indicated some attributing sources of the heterogeneity. Besides, the results of subgroup analysis also indicated that BP use was significantly associated with increased risk of CRC for rectal cancer (RR $0.70 ; 95 \%$ CI 0.55 to 0.90 ), for male (RR $0.84,95 \%$ CI 0.76 to 0.92 ) or female (RR $0.85,95 \%$ CI 0.75 to 0.96 ) participants, while not for other subgroups. However, though the risk estimates did not reach statistical significance for those subgroups,most of the trends still indicated increased risk for BP use, probably resulting from the lack of statistical power with small sample size. More population-based prospective observational studies, which account for the sources of heterogeneity, would be needed to truly assess the effect of BPs on risk of CRC.

Our finding that BP use was significantly associated with reduced risk of CRC was consistent with the findings of four previously published meta-analyses [23-26]. However, this is the first meta-analysis including the survival analysis for association between BP use and CRC mortality. Though only three studies were involved for survival analyses with no significant associations observed, we found there are trends of survival benefits for diagnosed CRC patients with BP use. Therefore, we suggest an updated analysis proposed once there are sufficient number of studies published. However, caution should be taken when interpreting the results of current analyses.

Recently, several potential mechanisms may explain the association between BP intake and reduced CRC risk. It has been reported that BPs have antineoplastic effects in vitro in several cancer cell lines, including breast, prostate, multiple myeloma and lung cancer [27] through various mechanisms including inhibitory effect on angiogenesis, cell growth and metastases, and promoting

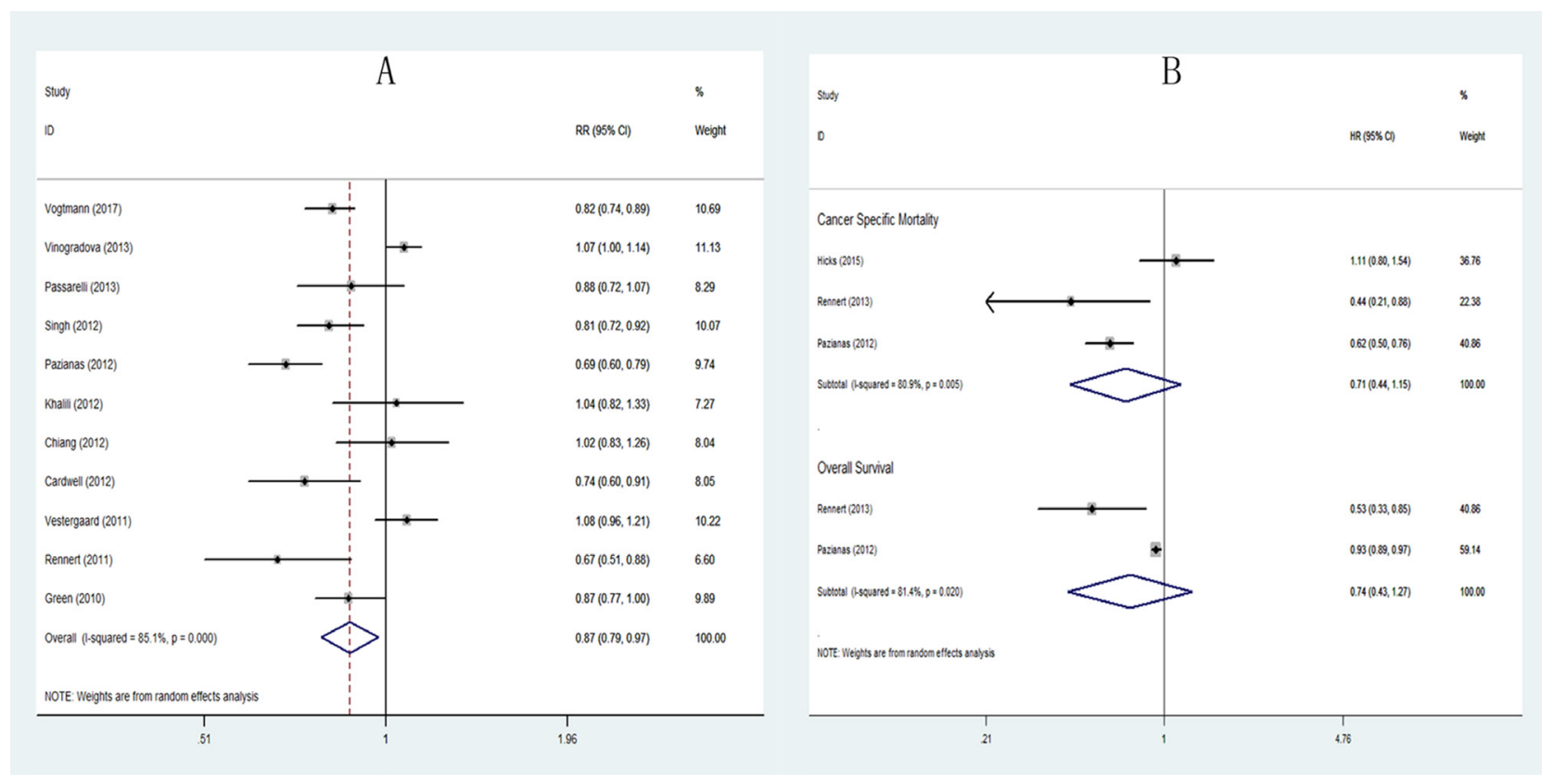

Figure 2: Forest plots for the associations between bisphosphonate intake and (A) risk/ (B) mortality of colorectal cancer using randomeffects models. 
Table 1: Subgroup analyses in subset of included studies according to baseline characteristics for associations between bisphosphonate use and CRC risk

\begin{tabular}{|c|c|c|c|c|c|}
\hline & $\mathbf{R R}$ & $95 \% \mathrm{CI}$ & $\begin{array}{c}\text { Heterogeneity } \\
(\%)\end{array}$ & $P$ & $\begin{array}{l}\text { No. of included } \\
\text { Studies }\end{array}$ \\
\hline Total & 0.87 & 0.79 to 0.97 & 85.1 & 0 & 11 \\
\hline $\begin{array}{l}\text { Study design } \\
\text { Nested case-control } \\
\text { Cohort }\end{array}$ & $\begin{array}{l}0.84 \\
0.93\end{array}$ & $\begin{array}{l}0.73 \text { to } 0.97 \\
0.76 \text { to } 1.13\end{array}$ & $\begin{array}{l}87.7 \\
84.8\end{array}$ & $\begin{array}{l}0 \\
0\end{array}$ & $\begin{array}{l}6 \\
5\end{array}$ \\
\hline $\begin{array}{l}\text { Research region } \\
\text { USA/Canada. } \\
\text { Europe } \\
\text { Asia }\end{array}$ & $\begin{array}{l}0.84 \\
0.88 \\
0.83\end{array}$ & $\begin{array}{l}0.78 \text { to } 0.92 \\
0.74 \text { to } 1.06 \\
0.55 \text { to } 1.26\end{array}$ & $\begin{array}{c}21.2 \\
91 \\
82.6\end{array}$ & $\begin{array}{c}0.283 \\
0 \\
0.016\end{array}$ & $\begin{array}{l}4 \\
5 \\
2\end{array}$ \\
\hline $\begin{array}{l}\text { BP type } \\
\text { Alendronate } \\
\text { Etidronate } \\
\text { Risedronate }\end{array}$ & $\begin{array}{l}1.05 \\
0.96 \\
0.78\end{array}$ & $\begin{array}{l}0.91 \text { to } 1.20 \\
0.84 \text { to } 1.09 \\
0.39 \text { to } 1.55\end{array}$ & $\begin{array}{l}63.4 \\
50.4 \\
85.6\end{array}$ & $\begin{array}{l}0.065 \\
0.133 \\
0.008\end{array}$ & $\begin{array}{l}3 \\
3 \\
2\end{array}$ \\
\hline $\begin{array}{l}\text { Sex } \\
\quad \text { Male } \\
\text { Female }\end{array}$ & $\begin{array}{l}0.84 \\
0.85\end{array}$ & $\begin{array}{l}0.76 \text { to } 0.92 \\
0.75 \text { to } 0.96\end{array}$ & $\begin{array}{c}0 \\
53.2\end{array}$ & $\begin{array}{l}0.704 \\
0.046\end{array}$ & $\begin{array}{l}2 \\
6\end{array}$ \\
\hline $\begin{array}{l}\text { Tumor site } \\
\text { Left colon } \\
\text { Right colon } \\
\text { Rectum }\end{array}$ & $\begin{array}{l}0.71 \\
0.68 \\
0.70\end{array}$ & $\begin{array}{l}0.40 \text { to } 1.25 \\
0.41 \text { to } 1.12 \\
0.55 \text { to } 0.90\end{array}$ & $\begin{array}{c}72.9 \\
71.4 \\
0\end{array}$ & $\begin{array}{l}0.055 \\
0.061 \\
0.363\end{array}$ & $\begin{array}{l}2 \\
2 \\
2\end{array}$ \\
\hline
\end{tabular}

Abbreviations: $\mathrm{CI}=$ confidence intervence, $\mathrm{RR}=$ relative risk .

effect on tumor cell apoptosis and synergistic activity with cytotoxic chemotherapy [28-32]. However, the rationale for the result of the subgroup analyses has not been fully determined. Maybe only until some large-scale population-based cohort studies are conducted could we further determined this association and further investigate the true rationale.

Previous meta-analyses have reported the associations between $\mathrm{BP}$ use and $\mathrm{CRC}$ risk and all of them demonstrated that BP intake offers a protective effect against CRC [2326]. However, due to the limited number of studies (range 4 to 8 ) and relative small sample size (range, 392106 to 859709), there lack sufficient statistical power to draw a definite conclusion, so there is an urgently need to update the evidence for this topic to further clarify this associations.

This meta-analysis has several strengths. Firstly, it has the largest sample size with about four fold of the previously one, providing the most robust statistical evidence for the substantial risk estimate of CRC among BP users. Secondly, we comprehensively conducted major database search with no language or publication type limitations, minimizing the risk of publication bias. Thirdly, subgroup analyses had been done based on potential attributing sources of heterogeneity including study design, participant characteristics and BP exposure type, and the results were mostly similar with the primary analysis. Fourthly, we cross-checked the suitable studies, developed a data abstract form, abstracted each study data, assess the risk of bias by two independent authors, minimizing the selection bias or confouding. Though we found little evidence of publication bias, it cannot be thoroughly excluded.

We have proposed that the findings of this study can guide the clinician properly select candidates in specific stratum to use BP, evaluate their CRC risk who may benefit from BP use. These strata include some of the reported risk factors of CRC, such as body mass index, eating habits, physical activity, family history of CRC,etc.

Our study still has several limitations as with other meta-analyses. Firstly, most of the studies did not provide detailed study data concerning BP use duration or dose, so dose or duration dependent analyses could not be performed. Secondly, though we had done subgroup analyses according to some available data such as BP type, tumor location or participant gender etc., as there were few studies involved in most of the subgroups, we still could not draw definite conclusions from those subgroups. Thirdly, we noted that there existed difference in terms of adjustment variables among each study which might have resulted in heterogeneity due to statistical analyses. Such heterogeneity could have affected the accuracy and precision of the summary risk estimates. Finally, unpublished gray literature were not included, which could have resulted in publication bias.

In summary, our findings suggest that oral BP use may be associated with reduced risk of $\mathrm{CRC}$, while further 
larger cohort studies should be advocated to determine the true relationship between BP use and CRC mortality in specific patients. Future studies should explore the variation in the associations between BP type, dose and duration of BP use, and other drugs taken, such as aspirin, statins, glucose-lowering agents as statistical covariate adjustments and CRC risk or survival.

\section{MATERIALS AND METHODS}

\section{Search strategy}

We performed a systematic literature search of three relevent databases including Pubmed, Embase and Cochrane Library from initial to August 2017 for all studies investigating associations between BP use and $\mathrm{CRC}$ risk and survival. Supplementary Appendix provides the database search strategies using the following key words along with MeSH/EMTREE terms: "colon*/rectum/rectal/colorect*","cancer*/tumo?r*/ carcinom*/neoplas*/adenocarcinoma* /malignan*", "bisphosphonate*/diphosphonate*", and/or "prognos*/ survival/recurren*/ mortality/ predict*/outcome*/death". Additional relevant papers were identified through a manual reference search of all references listed in the primary selected studies, reviews or meta-analyses which were not found by database search. Date or language restrictions were not applied to our search strategies.

\section{Study selection and inclusion criteria}

Two reviewers (KX and GP) independently screened and evaluated all the citations identified through database search, then excluded all the irrelevant citations and left all the potentially relevant ones for full text review. Disagreements were resolved by discussion or by consultation of the senior author (YCZ).

Observational studies including cohort or nested case-control studies were considered eligible if they fulfilled the following criteria: studies published with original data with the outcome of interest being risk or survival of CRC; the study of interest was BP use at the diagnosis of $\mathrm{CRC}$ with the RR or HR estimates and corresponding 95\% CIs available comparing risk or mortality of BP users with that of in non-users. For the overlapped or duplicated data sets, we only used the most detailed or recent one for data abstraction. We did not contact the corresponding authors for missing data.

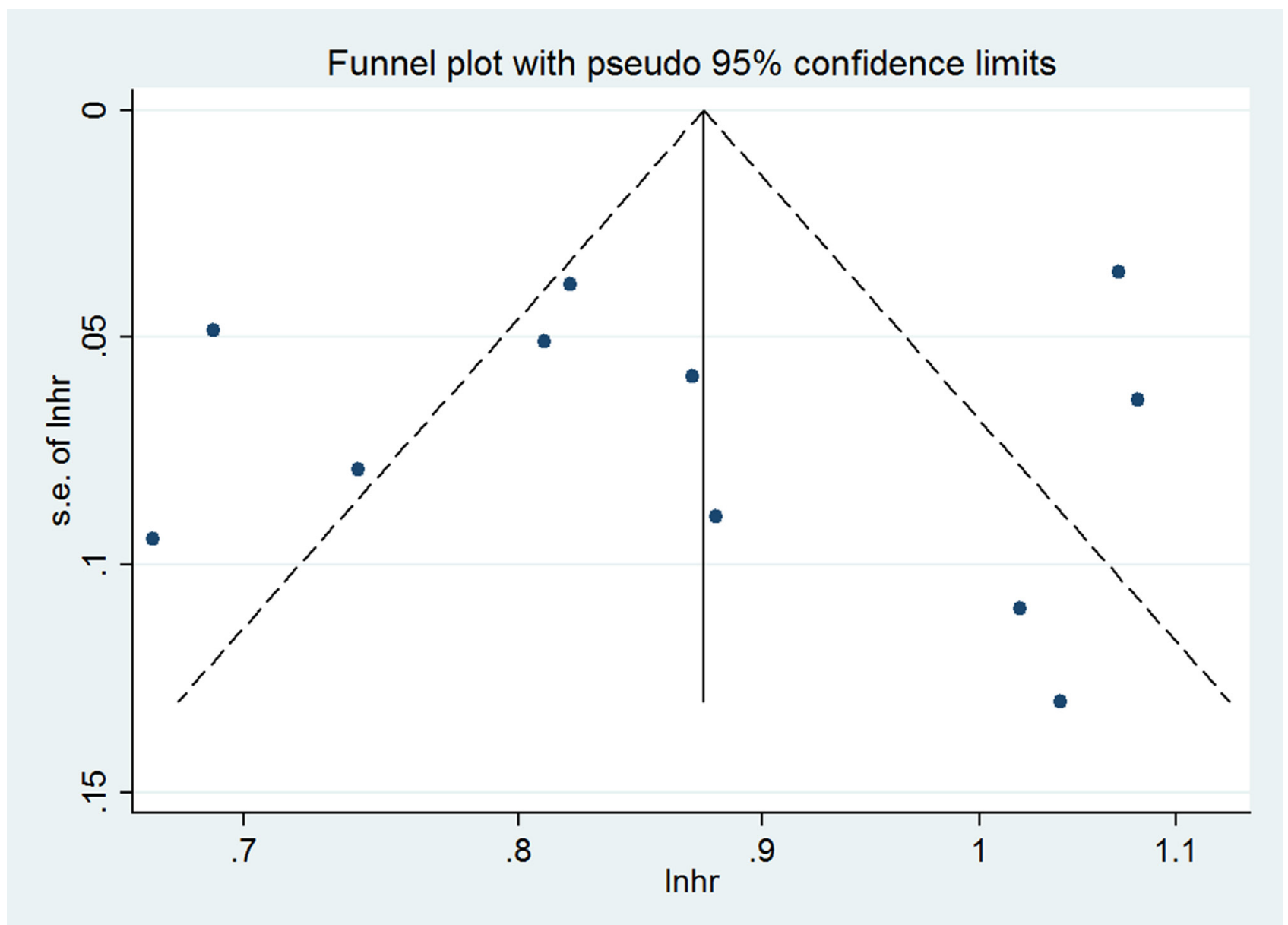

Figure 3: Funnel plot for meta-analysis of the association between bisphosphonate intake and risk of colorectal cancer. 


\section{Data abstraction and study quality assessment}

Two authors independently extracted data from included studies using a predesigned data abstraction form for each study including the following study characteristics: the name of the first author, publication year, study design, study region, sex, age, the sample size of the full cohort, type of BP, definition of exposure, measure of exposure, mean or median follow-up period, adjusted variables.

Nine-star Newcastle-Ottawa Scale (NOS) instrument was applied to evaluate study quality as a validated tool for the assessment of the methodological quality of observational studies based on selection of study participants, comparability of study groups, and adequacy of outcome assessment [33]. These three domains were allocated to nine points. We defined a score of more than 6 as high quality.

\section{Statistical analysis}

Meta-analyses were performed using Stata version 12.0 (StataCorp LP, College Station, Texas, USA). Summary RRs/HRs were combined using the DerSimonian and Laird random effects model [34] and publication bias was assessed by visual inspection of the funnel plot symmetry and Begg's or Egger's test [35, 36], with a $P$ value less than 0.1 indicating statistically significant. Inter-study heterogeneity was examined by $\mathrm{I}^{2}$ statistic with an $\mathrm{I}^{2}$ value $>50 \%$ defining as statistical heterogeneity. Subgroup analyses were also conducted to explore the potential source of heterogeneity by some baseline variables. Duval's non-parametric trim-and-fill method was used as a method of sensitivity analysis to test the robustness of the pooled results [37]. Since a nested case-control study draws its cases and controls from a cohort population. This cohort, at its inception or during the period of follow-up, has had exposure information gathered of interest to the investigator with the advantage of minimised selection bias or recall bias compared with a case-control study [38]. The risk estimate of a nestedcase control study is quite similar to that of a cohort study. Thus, we combined the summary estimates of those two kinds of studies together.

\section{CONFLICTS OF INTEREST}

The authors declare no competing financial interests.

\section{FUNDING}

This work was financially supported by National Natural Science Foundation of China (No. 81502657).

\section{REFERENCES}

1. Kanis J, Burlet N, Cooper C, Delmas P, Reginster J, Borgstrom F, Rizzoli R; European Society for Clinical and Economic Aspects of Osteoporosis and Osteoarthritis (ESCEO). European guidance for the diagnosis and management of osteoporosis in postmenopausal women. Osteoporosis international. 2008; 19:399-428.

2. Qaseem A, Snow V, Shekelle P, Hopkins R, Forciea MA, Owens DK. Pharmacologic Treatment of Low Bone Density or Osteoporosis to Prevent Fractures: A Clinical Practice Guideline from the American College of PhysiciansTreatment of Low Bone Density or Osteoporosis to Prevent Fractures. Annals of internal medicine. 2008; 149:404-415.

3. Watson J, Wise L, Green J. Prescribing of hormone therapy for menopause, tibolone, and bisphosphonates in women in the UK between 1991 and 2005. European journal of clinical pharmacology. 2007; 63:843-849.

4. Van Poznak CH, Temin S, Yee GC, Janjan NA, Barlow WE, Biermann JS, Bosserman LD, Geoghegan C, Hillner BE, Theriault RL. American Society of Clinical Oncology executive summary of the clinical practice guideline update on the role of bone-modifying agents in metastatic breast cancer. Journal of Clinical Oncology. 2011; 29:1221-1227.

5. Gnant M, Clézardin P. Direct and indirect anticancer activity of bisphosphonates: a brief review of published literature. Cancer treatment reviews. 2012; 38:407-415.

6. Green J, Clézardin P. The molecular basis of bisphosphonate activity: a preclinical perspective. Seminars in oncology: Elsevier, pp. S3-S11.

7. Pazianas M, Russell RG. Potential therapeutic effects of oral bisphosphonates on the intestine. Annals of the New York Academy of Sciences. 2011; 1240.

8. Sewing L, Steinberg F, Schmidt H, Göke R. The bisphosphonate zoledronic acid inhibits the growth of HCT116 colon carcinoma cells and induces tumor cell apoptosis. Apoptosis. 2008; 13:782-789.

9. Rennert G, Pinchev M, Rennert HS, Gruber SB. Use of bisphosphonates and reduced risk of colorectal cancer. Journal of clinical oncology. 2011; 29:1146-1150.

10. Green J, Czanner G, Reeves G, Watson J, Wise L, Beral V. Oral bisphosphonates and risk of cancer of oesophagus, stomach, and colorectum: case-control analysis within a UK primary care cohort. BMJ. 2010; 341:c4444.

11. Cardwell CR, Abnet CC, Veal P, Hughes CM, Cantwell MM, Murray LJ. Exposure to oral bisphosphonates and risk of cancer. International journal of cancer. 2012; 131:E717-725.

12. Singh H, Nugent Z, Demers A, Mahmud S, Bernstein C. Exposure to bisphosphonates and risk of colorectal cancer: a population-based nested case-control study. Cancer. 2012; 118:1236-1243.

13. Vestergaard P. Occurrence of gastrointestinal cancer in users of bisphosphonates and other antiresorptive drugs against osteoporosis. Calcified tissue international. 2011; 89:434-441.

14. Hicks BM, Murray LJ, Hughes C, Cardwell CR. Postdiagnostic oral bisphosphonate use and colorectal cancer mortality: a population-based cohort study within the UK 
Clinical Practice Research Datalink. British journal of cancer. 2015; 113:123-126.

15. Rennert G, Rennert H, Pinchev M, Flugelman A, Kershenbaum A, Landsman K, Hadad R, Shulman K, Gruber S. Abstract P3-06-03: Oral bisphosphonates and survival of breast and colon malignancies. AACR.

16. Pazianas M, Abrahamsen B, Eiken PA, Eastell R, Russell RG. Reduced colon cancer incidence and mortality in postmenopausal women treated with an oral bisphosphonate--Danish National Register Based Cohort Study. Osteoporosis international. 2012; 23:2693-2701.

17. Vogtmann E, Corley DA, Almers LM, Cardwell CR, Murray LJ, Abnet CC. Oral bisphosphonates and colorectal cancer. Sci Rep. 2017; 7:44177.

18. Vinogradova Y, Coupland C, Hippisley-Cox J. Exposure to bisphosphonates and risk of gastrointestinal cancers: series of nested case-control studies with QResearch and CPRD data. BMJ. 2013; 346:f114.

19. Passarelli MN, Newcomb PA, LaCroix AZ, Lane DS, Ho GY, Chlebowski RT. Oral bisphosphonate use and colorectal cancer incidence in the Women's Health Initiative. Journal of bone and mineral research. 2013; 28:2043-2048.

20. Khalili H, Huang ES, Ogino S, Fuchs CS, Chan AT. A prospective study of bisphosphonate use and risk of colorectal cancer. Journal of clinical oncology. 2012; 30:3229-3233.

21. Chiang $\mathrm{CH}$, Huang $\mathrm{CC}$, Chan WL, Huang PH, Chen TJ, Chung CM, Lin SJ, Chen JW, Leu HB. Oral alendronate use and risk of cancer in postmenopausal women with osteoporosis: A nationwide study. Journal of Bone and Mineral Research. 2012; 27:1951-1958.

22. Vestergaard P. Occurrence of gastrointestinal cancer in users of bisphosphonates and other antiresorptive drugs against osteoporosis. Calcified tissue international. 2011; 89:434-441.

23. Yang G, Hu H, Zeng R, Huang J. Oral bisphosphonates and the risk of colorectal cancer: a meta-analysis. Journal of clinical gastroenterology. 2013; 47:741-748.

24. Thosani N, Thosani SN, Kumar S, Nugent Z, Jimenez C, Singh H, Guha S. Reduced risk of colorectal cancer with use of oral bisphosphonates: a systematic review and metaanalysis. Journal of clinical oncology. 2013; 31:623-630.

25. Singh S, Singh AG, Murad MH, Limburg PJ. Bisphosphonates are associated with reduced risk of colorectal cancer: a systematic review and meta-analysis. Clinical gastroenterology and hepatology. 2013; 11:232239.e231.

26. Bonovas S, Nikolopoulos G, Bagos P. Bisphosphonate use and risk of colorectal cancer: a systematic review and metaanalysis. British journal of clinical pharmacology. 2013; 329-337.
27. Green JR. Bisphosphonates: preclinical review. The oncologist. 2004; 9:3-13.

28. Senaratne S, Mansi J, Colston K. The bisphosphonate zoledronic acid impairs membrane localisation and induces cytochrome c release in breast cancer cells. British journal of cancer. 2002; 86:1479.

29. Santini D, Vincenzi B, Dicuonzo G, Avvisati G, Massacesi C, Battistoni F, Gavasci M, Rocci L, Tirindelli MC, Altomare V. Zoledronic acid induces significant and long-lasting modifications of circulating angiogenic factors in cancer patients. Clinical Cancer Research. 2003; 9:2893-2897.

30. Meunier P, Alexandre C, Edouard C, Mathieu L, Chapuy M, Bressot C, Vignon E, Trechsel U. Effects of disodium dichloromethylene diphosphonate on Paget's disease of bone. The Lancet. 1979; 314:489-492.

31. Mahtani R, Jahanzeb M. Bisphosphonates as anticancer therapy for early breast cancer. Clinical breast cancer. 2010; 10:359-366.

32. Boissier S, Ferreras M, Peyruchaud O, Magnetto S, Ebetino FH, Colombel M, Delmas P, Delaissé JM, Clézardin P. Bisphosphonates inhibit breast and prostate carcinoma cell invasion, an early event in the formation of bone metastases. Cancer research. 2000; 60:2949-2954.

33. Stang A. Critical evaluation of the Newcastle-Ottawa scale for the assessment of the quality of nonrandomized studies in meta-analyses. European journal of epidemiology. 2010; 25:603-605.

34. Deeks JJ, Altman DG, Bradburn MJ. Statistical methods for examining heterogeneity and combining results from several studies in meta-analysis. Systematic Reviews in Health Care: Meta-Analysis in Context, Second Edition. 2008:285-312.

35. Egger M, Smith GD, Schneider M, Minder C. Bias in metaanalysis detected by a simple, graphical test. BMJ. 1997; 315:629-634.

36. Begg CB, Mazumdar M. Operating characteristics of a rank correlation test for publication bias. Biometrics. 1994:10881101.

37. Duval S, Tweedie R. Trim and fill: a simple funnel-plotbased method of testing and adjusting for publication bias in meta-analysis. Biometrics. 2000; 56:455-463.

38. Sedgwick P. Nested case-control studies: advantages and disadvantages. BMJ. 2014; 348. 